\title{
AS DESPESAS FAMILIARES COM EDUCAÇÃO NO BRASIL E A COMPOSIÇÃO DE GÊNERO DO GRUPO DE IRMÃOS*
}

\author{
Sérgio Carlos de Carvalho ${ }^{\dagger}$ \\ Ana Lúcia Kassouf ${ }^{\ddagger}$
}

\begin{abstract}
Resumo
Estudou-se a existência de viés de gênero nas escolhas paternas em gastar recursos na educação da prole. Obteve-se uma amostra de famílias da Pesquisa de Orçamentos Familiares (POF) 2002-2003, do Instituto Brasileiro de Geografia e Estatística (IBGE). Foram utilizados modelos Tobit para estimar curvas de Engel das despesas familiares com educação e de gastos com grupos de itens dessas despesas, como função das características socioeconômicas e demográficas das famílias. Foram utilizados testes de Wald para verificar a igualdade dos parâmetros estimados do número de filhos e filhas matriculados. Tais testes não indicaram discriminação contra as filhas nos desembolsos com educação.
\end{abstract}

Palavras-chave: Viés de gênero, Despesas educacionais, Curva de Engel, Regressão censurada Tobit.

\begin{abstract}
This paper analyses the existence of a gender bias in the parents' decisions when they spend money on the education of their children. A sample of families is obtained from a Household Budget Survey (POF) collected in 2002-2003, by the Brazilian Institute of Geography and Statistic (IBGE). Tobit models are used to estimate Engel curves for the family education expenses and expenditures with educational items, as a function of socioeconomic and demographic characteristics of the households. Wald tests are used to check the equality of the parameters estimated with the number of enrolled sons and daughters. Such tests do not indicate discrimination against daughters regarding educational fees.
\end{abstract}

Palavras-chave: Gender bias, Educational expenditure, Engel curve, Tobit censored regression.

JEL classification: I21, J16, J71

\footnotetext{
* Os autores agradecem a José Adrian Payeras pelas sugestões feitas na versão preliminar do trabalho e agradecem, também, ao IBGE/Diretoria de Pesquisa/Coordenadoria de Índices de Preços/Gerência de Pesquisa de Orçamentos Familiares pelas informações sobre a POF2002-2003 utilizadas nesse trabalho.

† Professor do Departamento de Economia,Universidade Estadual de Londrina-UEL. Endereço para contato: Rodovia Celso Garcia Cid, Pr Km445 Km 380, Campus Universitário, Cx. Postal 6001, Londrina-PR CEP. 86051-990. E-mail: ssergio@uel.br.

‡ Professora do Departamento de Economia da ESALQ-USP. E-mail: alkassou@esalq.usp.br.
} 


\section{Introdução}

O menor acesso feminino ao ensino ocorre em várias regiões do mundo. A maioria das crianças matriculadas encontra-se em regiões nas quais as meninas são sub-representadas em algum nível educacional: na educação primária, $52,7 \%$ moram em regiões com sub-representação feminina; no primeiro ciclo da educação secundária, $45,1 \%$ e no segundo ciclo da educação secundária, 72,8\% (UNESCO, 2005). No ensino superior de 65 países em desenvolvimento com dados completos sobre educação, apenas $8 \%$ apresentam paridade de gênero no acesso a esse nível de ensino (Unidas 2005).

O panorama acima não ocorre no Brasil, pois a participação das mulheres no sistema educacional é superior à dos homens. Entre as pessoas de 10 anos de idade ou mais, os homens têm uma taxa de analfabetismo maior, 10,8\%, contra 10,2\% das mulheres (IBGE 2004). Na mesma faixa etária, as mulheres têm, em média, mais anos de estudos, 6,7 anos, contra 6,4 dos homens (IBGE 2004). Além disso, no ensino médio as mulheres são $54,1 \%$ e no ensino superior 57,3\% (IBGE 2004).

Apesar do cenário favorável à escolarização feminina, algumas ressalvas podem ser levantadas. Beltrão (2002) detectou um padrão de comportamento diferenciado entre os gêneros na obtenção da escolarização, pois as mulheres completaram os estudos mais jovens que os homens. Todavia, em coortes mais velhas os homens superaram as mulheres em escolaridade, uma vez que foram concluintes defasados. Portanto, a melhor escolarização das jovens em uma coorte pode não se manter com o passar do tempo. A composição demográfica da família pode afetar garotas e garotos de maneira diferente, pois a presença de menores de 14 anos e de idosos na família reduz a probabilidade de os filhos freqüentarem a escola em uma proporção maior para as garotas do que para os garotos (Conseuil 2001). Existe uma segmentação do acesso às carreiras universitárias, levando as mulheres a escolherem carreiras com menos status e prestígio, geralmente com menor remuneração (Beltrão e Teixeira 2005).

As meninas e mulheres brasileiras têm um melhor ambiente educacional do que as meninas e mulheres dos demais países em desenvolvimento, mas isso não descarta a possível existência de discriminação educacional. Um exemplo está na segmentação do acesso às carreiras universitárias, que leva as mulheres a escolherem aquelas que apresentam expectativa de menores remunerações futuras (Beltrão e Teixeira 2005). Outra forma de discriminação seria os pais escolherem escolas diferentes para filhos e filhas, matriculando os filhos em escolas mais distantes e de melhor qualidade, e as filhas em escolas mais próximas de casa, mesmo sendo de qualidade inferior. O tempo que os pais utilizam para orientar os filhos e filhas, quando estes executam tarefas escolares, poderia ser diferente conforme o sexo da criança.

Diante das várias formas de discriminação com as quais os garotos e garotas podem se deparar durante sua formação educacional, a proposta deste trabalho é estudar se as escolhas paternas em realizar despesas educacionais apresentam viés de gênero.

\section{Revisão de literatura}

Um arcabouço teórico comumente utilizado para abordar a questão acima é o que relaciona as decisões familiares de investir no capital humano dos filhos e 
filhas e a restrição de recursos familiares. Por esse arcabouço, pode-se conceber um modelo econômico segundo o qual as crianças disputam entre si os recursos escassos da família. Assim, o crescimento do número de crianças pode reduzir a quantidade de recursos que cada uma recebe. As famílias, tentando maximizar o retorno total futuro de suas crianças, poderiam discriminar a alocação de recursos no presente, utilizando como critério, por exemplo, o gênero. Vários trabalhos podem ser citados como exemplo da utilização desse arcabouço teórico para explicar o viés de gênero nas escolhas paternas em alocar recursos para a formação dos filhos e filhas, entre os quais se encontram Garg e Morduch (1998), Morduch (2000), Post (2001) e Ono (2004).

Os modelos econômicos de decisão familiar não são os únicos utilizados para explicar a diferença educacional entre os gêneros. Butcher e Case (1994) consideram o modelo de grupo de referência mais adequado para o problema de viés de gênero na educação. Neste modelo, uma menina criada somente com meninos os teria como grupo de referência e adquiriria as habilidades e atitudes que facilitariam seu desempenho no ambiente educacional favorável aos meninos.

A comparação dos resultados mostra que em alguns casos eles são conflitantes, embora em outros não. Por exemplo, Garg e Morduch (1998) deduzem que a presença de um menino no grupo de irmãos reduz a chance de uma menina freqüentar o segundo grau. Por esta dedução, uma menina com dois meninos no grupo de irmãos estaria em pior situação do que uma menina com duas irmãs, na disputa por recursos educacionais. Isso conflita com Butcher e Case (1994), pois seus resultados levam a concluir que uma menina com dois meninos no seu grupo de irmãos estaria em vantagem, em relação a uma menina com duas outras meninas. Por outro lado, Ono (2004), Post (2001) e Morduch (2000), principalmente Morduch (2000) para a Tanzânia, reforçam as evidências de Garg e Morduch (1998).

Alguns trabalhos empíricos, procurando explicar o avanço educacional dos brasileiros, em especial das mulheres brasileiras, serviram-se do arcabouço teórico que relaciona as decisões familiares de investir em capital humano dos filhos às restrições de recursos familiares. Dois trabalhos se destacam: Marteleto (2002), que relacionou o tamanho da família e o gênero das crianças aos diferenciais educacionais entre garotos e garotas, no Brasil, nas últimas décadas do século XX; e Pierotti (2004), que investigou a relação entre a composição de gênero de um grupo de irmãos e as decisões paternas de investimento em capital humano, utilizando os dados da Pesquisa Nacional de Amostras de Domicílios (PNAD), de 1992 a 1999.

Marteleto (2002) e Pierotti (2004) acharam evidências da rivalidade entre irmãos e também apontaram discriminação de gênero. As considerações de Marteleto (2002) reforçam o quadro favorável à escolarização feminina e sugerem que a divisão de tarefas no auxílio à manutenção familiar, com a queda do tamanho das famílias que ocorreu com a transição demográfica, ${ }^{1}$ favoreceu as meninas. Pierotti (2004) reconhece a maior escolarização feminina, em relação à masculina, e a maior propensão masculina ao trabalho fora do lar, em especial se comparada à propensão das garotas com grande presença masculina no seu grupo de irmãos. Com isso, os dois trabalhos apresentam se-

\footnotetext{
1 Transição demográfica é a mudança da base de crescimento populacional, de taxas de mortalidade e fecundidade altas, para taxas de mortalidade e fecundidade baixas. No Brasil, este processo ocorreu mais rapidamente do que, por exemplo, em alguns países europeus (Beltrão 2004).
} 
melhanças, e reforçam a idéia, presente em Barros e Mendonça (1990), de que há especialização de gênero na divisão do trabalho dentro do grupo de irmãos, o que seria favorável à educação feminina. Neste sentido, a discriminação de gênero parece ser pró-feminina.

Embora apresente semelhança com Marteleto (2002), Pierotti (2004) não destaca um possível viés pró-feminino na educação, por dois motivos. O primeiro é que as garotas mais propensas a estar fora da série adequada à idade eram as que tinham maior presença masculina no grupo de irmãos, ainda que o atraso escolar das garotas tenha sido menor do que o dos garotos. O segundo é a menor escolaridade das mulheres que não estavam mais na casa dos pais.

\section{Metodologia}

Neste artigo a questão do diferencial de gênero na educação é tratada com um procedimento metodológico diferente daqueles procedimentos utilizados na literatura para abordar o caso brasileiro. A base de dados que contém informações sobre as despesas familiares é a Pesquisa de Orçamentos Familiares (POF), do Instituto Brasileiro de Geografia e Estatística (IBGE). São utilizadas curvas de Engel, que fornecem uma abordagem indireta para estudos sobre viés de gênero na alocação intra-domiciliar das despesas de consumo (Kingdon 2005) Nessa abordagem, a composição de gênero da família é um dos fatores explicativos dos gastos familiares com um bem (Kingdon 2005). Este método é empregado por ser mais adequado por observar os dados da POF por família e não por indivíduo.

\subsection{A forma funcional utilizada}

O modelo para a curva de Engel deste artigo é do tipo duplo-log, semelhante ao adotado por Prais (1955), acrescido das variáveis socioeconômicas e demográficas ajustadas ao interesse do trabalho. Uma vantagem é que isso pode amenizar um eventual problema de heterocedasticiade (Tansel e Bircan 2006).

Uma curva de Engel, do tipo duplo-log, não está livre de todas as restrições da Teoria da Demanda. Essa curva apresenta: a) homogeneidade de grau zero das funções preço e renda; b) simetria na substituição entre os bens; e c) negatividade do efeito substituição (Medeiros 1978). Resta, no entanto, a restrição de aditividade, pois a função duplo-log não é inteiramente consistente com essa restrição (Medeiros 1978).

As curvas que melhor se ajustam aos dados, porém, não são as aditivas. Com isso, uma boa estimativa por produto pode levar a um erro na renda total disponível para consumo ou, então, se garantida a aditividade, a demanda por produto pode não ser bem estimada (Gomes 2005). Neste artigo, propõese estimar uma função de despesas com educação e também desagregar essas despesas em vários itens, o que pode trazer problemas adicionais à estimação. Em razão disso, optou-se por uma forma funcional que fosse capaz de proporcionar um melhor ajuste aos dados disponíveis.

No trabalho de Prais (1955), a curva de Engel duplo-log forneceu as melhores estimativas para todos os bens e serviços, à exceção de alimentos (Mahan 1979). Além disso, Houthakker (1965), embora reconheça a falha da não aditividade presente na função duplo-log, afirma que não existem sérios rivais quanto à qualidade do ajuste, facilidade de estimação e à interpretação imediata dos resultados. 
A forma específica utilizada no presente no artigo é:

$$
E d u_{i}=\alpha_{i}+\beta_{i} \log \left(\frac{x_{i}}{n_{i}}\right)+\sum_{k=1}^{k} \gamma_{k i} m_{k i}+\sum_{j=1}^{j} \delta_{j i} f_{j i}+\tau_{i} z_{i}+u_{i},
$$

em que $E d u$ é o logaritmo das despesas educacionais da família $i ; x_{i}$ são as despesas totais da família i; $n_{i}$ é o número de pessoas da família $i ; m_{k i}$ é o número de pessoas na família $i$, em uma classe $k$ que distingue idade, exclusive filhos e filhas matriculados e não matriculados; $f_{j i}$ é o número de filhos e filhas matriculados e não matriculados, em que uma classe $j$ distingue idade, sexo e se está matriculado ou não; $z_{i}$ é um vetor de variáveis socioeconômicas da família $i$; $u_{i}$ é o termo de erro associado à família $i$.

Testes de hipótese são feitos para verificar a preferência dos pais em alocar mais recursos para a educação dos filhos ou das filhas matriculados. Esses testes comparam aqueles coeficientes estimados $\delta_{j i}$ que representam o número de filhos e filhas matriculados. Se os $\delta_{j i}$ são diferentes, há a evidência de discriminação de gênero na alocação de recursos educacionais (Kingdon 2005).

\subsection{O modelo Tobit}

A amostra foi obtida entre as unidades de consumo da POF 2002-2003, consideradas para os fins deste trabalho como famílias. Foram selecionadas todas as famílias com filhos e filhas entre 7 e 20 anos, com ao menos um ou uma matriculado(a) no ensino regular. Famílias com algum membro da família matriculado, que não filho ou filha, foram excluídas. A amostra da pesquisa foi composta por 11.386 famílias, das quais 9.320 tiveram desembolsos com educação e 2.066 famílias não tiveram.

O fato de algumas famílias não apresentarem despesas com educação pode ter sido gerado por vários motivos. As unidades de consumo ou os informantes não tiveram despesas registradas porque elas não foram realizadas no período de referência, ou porque elas foram pagas por outro informante ou unidade de consumo. ${ }^{2}$

O valor zero de uma variável dependente para um subconjunto da população pode ser resultado da escolha de um agente econômico em um problema de otimização, que levou a uma solução de canto (Wooldridge 2002). Então, a variável dependente assume valor zero para um número razoável de observações e é uma variável aleatória contínua para valores estritamente positivos.

Neste caso, um modelo conveniente para a análise econométrica é o modelo Tobit. James Tobin em 1956, fornece estimativas consistentes por Máxima Verossimilhança, no caso de amostras censuradas.

Neste artigo o modelo Tobit é desenvolvido com base em Wooldridge (2002), sendo:

$$
E d u^{*}=X \beta+u \quad \text { sendo } u \mid X \sim N\left(0, \sigma^{2}\right)
$$

e

$$
E d u=\max \left(0, E d u^{*}\right) .
$$

2 Informação fornecida em comunicação pessoal feita pelo IBGE/Diretoria de Pesquisa/Coordenação de Índice de preços/Gerência de Pesquisa de Orçamentos Familiares em resposta à solicitação referente ao Protocolo 6716-2007-1. 
A variável $E d u^{*}$ é uma variável latente não observada, construída artificialmente. O modelo necessita que $E d u^{*}$ tenha uma distribuição normal homocedástica. A variável $E d u$ representa a resposta observada, sendo: $E d u=E d u^{*}$, quando $E d u^{*} \geq 0 ; E d u=0$, quando $E d u^{*}<0$; e $E d u$ contínua quando estritamente positiva. Os outros componentes do modelo são: o vetor de variáveis explicativas $X$, o vetor de parâmetros $\beta$ e o termo de erro $u$.

Para um problema de solução de canto a $E(E d u \mid X)$ tem zero como o limite inferior. Portanto,

$$
E(E d u \mid X) \geq \max (0, X \beta) .
$$

A esperança condicional de $E d u$ é sempre não negativa, não dependendo da distribuição e da forma funcional de $E d u^{*}$.

A esperança condicional de $E d u$ pode ser definida explicitamente. Para isso $u$ tem de ser independente de $X$ e normalmente distribuído. Então,

$$
E(E d u \mid X)=P(E d u>0 \mid X) E(E d u \mid X) E(E d u \mid X, E d u>0) .
$$

Percebe-se que $E(E d u \mid X)$ para a sub-amostra não censurada é ponderada pela probabilidade condicional de uma observação de $E d u$ ser maior que zero. A expressão (5) é decomposta em duas partes. Na primeira tem-se

$$
P(E d u>0 \mid X)=P\left(\frac{u}{\sigma}>-\frac{X \beta}{\sigma}\right)=\Phi\left(\frac{X \beta}{\sigma}\right)
$$

Tendo $u \sim N\left(0, \sigma^{2}\right)$, então,

$$
E(u \mid u>-X \beta)=\sigma E\left(\frac{u}{\sigma} \mid \frac{u}{\sigma}>\frac{-X \beta}{\sigma}\right)=\sigma\left[\frac{\phi\left(\frac{-X \beta}{\sigma}\right)}{1-\Phi\left(\frac{-X \beta}{\sigma}\right)}\right]
$$

Se $E d u>0$ então $E d u=E d u *=X \beta+u$, por isso,

$$
E(E d u \mid X, E d u>0)=X \beta+\sigma\left[\frac{\phi\left(\frac{X \beta}{\sigma}\right)}{\Phi\left(\frac{X \beta}{\sigma}\right)}\right]
$$

A esperança condicional de $E d u$ é positiva para a subamostra censurada, quaisquer que sejam $X$ e $\beta$, e o segundo elemento do lado direito é $\sigma$, que multiplica a razão inversa de Mills.

Para um $X_{j}$ contínuo e não-relacionado a outros regressores, o efeito marginal condicional a $E d u>0$ é

$$
\frac{\partial E(E d u \mid X, E d u>0)}{\partial X_{j}}=\beta_{j} \Theta\left(\frac{X \beta}{\sigma}\right),
$$

em que $0<\Theta(X \beta / \sigma)<1$.

Para a sub-amostra censurada, o efeito marginal de $X_{j}$ sobre a esperança condicional de $E d u$ é uma ponderação do coeficiente $\beta_{j}$ por um fator de ajustamento, que, por sua vez, depende de $X$.

Retomando a esperança condicional para a amostra não censurada, equação (5), obtém-se:

$$
E(E d u \mid X)=\Phi\left(\frac{X \beta}{\sigma}\right) X \beta+\sigma \phi\left(\frac{X \beta}{\sigma}\right)
$$


Novamente tomando um $X_{j}$ contínuo e não relacionado a outros regressores é possível encontrar os efeitos marginais para a amostra não censurada. Derivando $E(E d u \mid X)$ em relação a $X_{j}$,

$$
\frac{\partial E(E d u \mid X)}{\partial X_{j}}=\Phi\left(\frac{X \beta}{\sigma}\right) \beta_{j}
$$

Assim, o efeito marginal não condicional é o resultado da ponderação de $\beta_{j}$ pela probabilidade de se obter uma resposta positiva, dado $X .^{3}$

\section{Descrição das variáveis}

As variáveis dependentes e independentes estão descritas na Tabela 1, juntamente com a média e desvio-padrão de cada uma delas. Como as variáveis dependentes estão na forma de logaritmo, o valor zero em algumas observações das despesas com educação ou dos gastos com os grupos de itens dessas despesas não permite que elas sejam identificadas para toda a amostra. Para contornar este problema, toma-se o logaritmo da soma de 1 mais as despesas com educação. Somar 1 e achar o logaritmo também foi feito para os gastos dos grupos de itens de despesas educacionais. Este procedimento foi utilizado por outros autores, como Alves (2001) e Tansel e Bircan (2006). Outra observação importante é que a despesa total mensal, incluindo os desembolsos com educação, ${ }^{4}$ é utilizada em substituição à renda mensal, pois ela é mais próxima da renda permanente da família e menos sujeita a erros de medida. Vários outros autores utilizaram procedimentos semelhantes como Bertasso (2007)

Os itens de desembolsos com educação estão agrupados em: "Mensalidades escolares", "Artigos escolares, livros e materiais bibliográficos", "Outras despesas escolares" e "Outros cursos" (Anexo A). "Mensalidades escolares" correspondem aos gastos familiares para que os filhos e filhas possam freqüentar os cursos do ensino fundamental, médio e superior em instituições privadas ou ainda cursos de pós-graduação lato sensu ou stricto sensu que cobram mensalidades, oferecidos por instituições privadas ou públicas. Os itens agregados em "Artigos escolares, livros e materiais bibliográficos", bem como os agregados em "Outras despesas escolares", correspondem, na sua maioria, aos gastos familiares com os bens e serviços necessários para os alunos frequentarem e acompanharem as aulas. Entre esses itens encontram-se uniformes, materiais didáticos diversos, livros, taxas escolares, alimentação, moradia, transporte, entre outros. Em "Outros cursos" estão agregados os itens que correspondem à formação complementar: cursos de idiomas, técnicoprofissionalizantes, culturais, relativos a atividades físicas etc. Esses cursos melhorariam as qualidades intelectuais, culturais e físicas dos filhos e filhas, além de fornecer uma formação técnico-profissional alternativa ou complementar à recebida por meio da frequência ao sistema educacional formal, em seus vários níveis.

Para controlar a presença de filhos e filhas matriculados são criadas 6 variáveis. Os filhos são divididos em 3 faixas etárias e a filhas em outras 3, idênticas. As duas primeiras, de 7 a 10 e de 11 a 14 anos, correspondem ao período em que a criança freqüenta o ensino fundamental. A faixa de 15 a 20

\footnotetext{
3 Para maiores detalhes sobre os efeitos marginais ver Wooldridge (2002, pp.521-523)

${ }^{4}$ As famílias gastam com educação em média 3,5\% de sua despesa total mensal (IBGE 2004).
} 
anos abrange os jovens que estão no ensino médio, mais os jovens que, eventualmente, não terminaram este período da formação escolar na idade esperada.

A presença de filhos e filhas não matriculados também é controlada por meio de 6 variáveis. As mesmas faixas etárias adotadas para separar filhos e filhas matriculados são adotadas. Estas variáveis procuram detectar a contribuição dos não matriculados para a alocação de recursos educacionais para os matriculados.

Espera-se que o crescimento do número de filhos e filhas aumente as despesas com educação, mas que a partir de certo ponto passe a ser uma restrição a esse aumento. Famílias muito numerosas podem ter que priorizar gastos com a sobrevivência imediata da prole, tendo que restringir a alocação de recursos educacionais. Para fazer esse controle, é utilizado o quadrado do total de filhos e filhas, matriculados ou não.

Além de pai, mãe, filhos e filhas, controlou-se a presença de outros membros da família por meio de 7 variáveis. Essas variáveis dividem as pessoas em 7 faixas etárias. O objetivo delas é idêntico ao das variáveis que controlam a presença de filhos e filhas não matriculados.

As famílias são classificadas segundo a cor ou raça da pessoa de referência, em quatro categorias: brancas, pretas, pardas e amarelas. Três variáveis binárias são criadas, sendo que a categoria das famílias brancas é a referência. Essas variáveis visam captar possíveis diferenças culturais que afetam as decisões familiares, quanto à escolarização dos filhos e filhas, e, também, a possível influência da participação dessas famílias na estrutura social proveniente de fatores étnicos.

As famílias são classificadas segundo a região. Elas estão classificadas em residentes nas regiões Sudeste, Nordeste, Norte, Sul e Centro Oeste. Três variáveis binárias controlam a região, sendo que as famílias do Sudeste servem de referência. As várias regiões brasileiras apresentam diferenças na infraestrutura necessária à educação. Os estados do Sul e Sudeste são superiores na oferta de escolas públicas e privadas, e também em outros aspectos estruturais que facilitam a freqüência à escola.

A área de residência também é utilizada para classificar as famílias em residentes na área urbana ou na área rural. Uma variável binária é criada para as famílias rurais, pois as famílias urbanas são utilizadas como referência. Isto procura controlar a diferença nas condições de acesso à educação das crianças e jovens das famílias rurais e urbanas.

Outras características familiares são controladas. A escolaridade da pessoa de referência e a do cônjuge, a presença ou não de cônjuge, o sexo da pessoa de referência, se os filhos e filhas frequentam apenas escolas privadas ou não.

Na Tabela 1, observa-se a composição dos filhos e filhas matriculados por faixa etária. A presença de meninas superou a de meninos apenas entre $7 \mathrm{e}$ 10 anos, nas demais faixas etárias verificou-se maior presença masculina. A maior presença entre as faixas etárias ocorreu entre os homens de 15 a 20 anos. Entre os filhos e filhas não matriculados a participação masculina superou a feminina, em todas as faixas etárias. A maior presença entre os não matriculados ocorreu também entre homens de 15 a 20 anos. Observa-se, ainda, pouco mais de dois filhos ou filhas por família.

Outras características familiares também são observadas na Tabela 1. As famílias que tinham filhos e filhas matriculados exclusivamente na rede privada chegaram a $17,5 \%$. Dentre elas, $77,6 \%$ eram chefiadas por homens, $19,2 \%$ eram uniparentais, $53,1 \%$ chefiadas por brancos e $29,1 \%$ por pardos. 
Tabela 1: Descrição das variáveis, médias e desvios-padrões ${ }^{a}$

\begin{tabular}{|c|c|c|c|}
\hline \multirow{2}{*}{ Variáveis } & \multirow{2}{*}{ Descrição das variáveis } & \multicolumn{2}{|c|}{ Brasil } \\
\hline & & média & d.p. \\
\hline \multicolumn{4}{|c|}{ Var. Dependentes ${ }^{b}$} \\
\hline Edu & Logaritmo das despesas familiares com educação & 2,599 & 1,966 \\
\hline Mensal_escol & Logaritmo dos gastos familiares com mensalidades escolares & 0,965 & 2,058 \\
\hline Art_livros & $\begin{array}{l}\text { Logaritmo dos gastos familiares com artigos escolares, livros e } \\
\text { materiais bibliográficos }\end{array}$ & 1,736 & 1,371 \\
\hline Outras_desp & Logaritmo dos gastos com outras despesas escolares & 0,434 & 1,090 \\
\hline Curs_naoregular & Logaritmo dos gastos com outras despesas escolares & 0,828 & 1,587 \\
\hline \multicolumn{4}{|c|}{ Var. Exógenas } \\
\hline Filhomatr7_10 & Filhos matriculados com mais de 6 anos e menos de 11 de idade & 0,297 & 0,526 \\
\hline Filhamatr7_10 & Filhas matriculadas com mais de 6 anos e menos de 11 de idade & 0,306 & 0,534 \\
\hline Filhomatr1 $\overline{1} \_14$ & $\begin{array}{l}\text { Filhos matriculados com mais de } 10 \text { anos e menos de } 15 \text { de } \\
\text { idade }\end{array}$ & 0,320 & 0,538 \\
\hline Filhamatr11_14 & $\begin{array}{l}\text { Filhas matriculadas com mais de } 10 \text { anos e menos de } 15 \text { de } \\
\text { idade }\end{array}$ & 0,319 & 0,534 \\
\hline Filhomatr15_20 & $\begin{array}{l}\text { Filhos matriculados com mais de } 14 \text { anos e menos de } 21 \text { de } \\
\text { idade }\end{array}$ & 0,335 & 0,574 \\
\hline Filhamatr15_20 & Filhas matriculadas com mais de 14 e menos de 21 de idade & 0,291 & 0,519 \\
\hline Filhonaomatr7_10 & $\begin{array}{l}\text { Filhos não matriculados com mais de } 6 \text { anos e menos de } 11 \text { de } \\
\text { idade }\end{array}$ & 0,006 & 0,080 \\
\hline Filhanaomatr7_10 & $\begin{array}{l}\text { Filhas não matriculadas com mais de } 6 \text { anos e menos de } 11 \text { de } \\
\text { idade }\end{array}$ & 0,004 & 0,061 \\
\hline Filhonaomatr11_14 & $\begin{array}{l}\text { Filhos não matriculados com mais de } 10 \text { anos e menos de } 15 \text { de } \\
\text { idade }\end{array}$ & 0,006 & 0,077 \\
\hline Filhanaomatr11_14 & $\begin{array}{l}\text { Filhas não matriculadas com mais de } 10 \text { anos e menos de } 15 \text { de } \\
\text { idade }\end{array}$ & 0,004 & 0,061 \\
\hline Filhonaomatr15_20 & $\begin{array}{l}\text { Filhos não matriculados com mais de } 14 \text { anos e menos de } 21 \text { de } \\
\text { idade }\end{array}$ & 0,089 & 0,318 \\
\hline Filhanaomatr15_20 & Filhas não matriculadas com mais de 14 e menos de 21 de idade & 0,063 & 0,258 \\
\hline Membro0_5 & Pessoas com menos de 6 anos de idade & 0,042 & 0,230 \\
\hline Membro6_10 & Pessoas com mais de 5 anos e menos de 11 de idade & 0,011 & 0,121 \\
\hline Membro11__14 & Pessoas com mais de 10 e menos de 15 de idade & 0,008 & 0,098 \\
\hline Membro15_20 & Pessoas com mais de 14 anos e menos de 21 de idade & 0,031 & 0,191 \\
\hline Membro21_27 & Pessoas com mais de 20 anos e menos de 28 de idade & 0,064 & 0,280 \\
\hline Membro28_61 & Pessoas com mais de 27 anos e menos de 62 de idade & 1,758 & 0,507 \\
\hline Membro62 & Pessoas acima de 61 anos de idade & 0,078 & 0,297 \\
\hline Filhtot2 & Quadrado do número de filhos e filhas & 5,219 & 5,870 \\
\hline Logrendper & Logaritmo da renda per capita & 5,457 & 1,019 \\
\hline Não_exclupriv & $\begin{array}{l}=1 \text { se filhos e filhas matriculados não exclusivamente no ensino } \\
\text { privado }\end{array}$ & 0,825 & 0,380 \\
\hline Exclupriv & $\begin{array}{l}=1 \text { se filhos e filhas matriculados exclusivamente no ensino pri- } \\
\text { vado }\end{array}$ & 0,175 & 0,380 \\
\hline Referenmascul & $=1$ se a pessoa de referência é do sexo masculino & 0,776 & 0,417 \\
\hline Referenfem & $=1$ se a pessoa de referência é do sexo feminino & 0,224 & 0,417 \\
\hline Escolrefer & Anos de escolaridade da pessoa de referência & 6,474 & 4,509 \\
\hline Escolconj & Anos de escolaridade do cônjuge & 5,316 & 4,652 \\
\hline Naoterconj & $=1$ se a família não tem cônjuge & 0,192 & 0,394 \\
\hline Terconj & $=1$ ter a família tem cônjuge & 0,808 & 0,394 \\
\hline Branca & $=1$ se a pessoa de referência é branca & 0,531 & 0,499 \\
\hline Preta & $=1$ se a pessoa de referência é preta & 0,074 & 0,261 \\
\hline Amarela & $=1$ se a pessoa de referência é amarela & 0,005 & 0,071 \\
\hline Parda & $=1$ se a pessoa de referência é parda & 0,391 & 0,488 \\
\hline Sudeste & $=1$ se a família reside no Sudeste & 0,443 & 0,497 \\
\hline Nordeste & $=1$ se a família reside no Nordeste & 0,248 & 0,432 \\
\hline Norte & $=1$ se a família reside no Norte & 0,063 & 0,244 \\
\hline Sul & $=1$ se a família reside no Sul & 0,171 & 0,376 \\
\hline Centro Oeste & $=1$ se a família reside no Centro Oeste & 0,074 & 0,262 \\
\hline Rural & $=1$ se a família reside na área rural & 0,146 & 0,353 \\
\hline Urbana & $=1$ se a família reside na área urbana & 0,854 & 0,353 \\
\hline
\end{tabular}

Fonte: Microdados da Pesquisa de Orçamentos Familiares de 2002-2003.

${ }^{a}$ Os resultados estão ponderados pelo fator de expansão da amostra.

${ }^{b}$ As variáveis dependentes são os logaritmos da soma de 1 mais as despesas que são de interesse nas análises econométricas. No Anexo A estão discriminados os itens referentes aos gastos com educação e como eles foram agregados para os fins deste trabalho. 
As regiões mais ricas, Sudeste e Sul, acolhiam $61,4 \%$ das famílias, sendo que, do total, $85,4 \%$ residiam no meio urbano. Em média, os chefes de família tinham mais anos de estudos do que os cônjuges.

\section{Resultados do modelo Tobit para as despesas com educação}

Neste artigo optou-se por estimar os efeitos marginais não condicionais. Eles permitem obter os efeitos das variáveis explicativas sobre as despesas médias com educação para todas as famílias, inclusive as que não efetuaram nenhum gasto educacional no período pesquisado. Para as regressões em que as variáveis dependentes eram os gastos com os diferentes itens educacionais o procedimento de estimar os efeitos marginais não condicionais foi mantido.

Os sinais dos parâmetros estimados para a presença de filhos e filhas matriculados foram positivos e significativos a $1 \%$, tendo as filhas maior impacto sobre as despesas educacionais (Tabela 2)..$^{5}$

Um teste de Wald verificou a igualdade entre as estimativas de matriculados em cada faixa etária. Os resultados indicaram que os parâmetros estimados para a faixa etária de 11 a 14 anos não foram diferentes, enquanto para as demais faixas foram a $5 \%$ para a faixa de 7 a 10 anos e a $1 \%$ de 15 a 20 anos (Tabela 3).

A presença de filhos e filhas não matriculados afetou positivamente as despesas educacionais (Tabela 2), o que pode significar que os filhos e filhas não matriculados não se apropriaram de uma parte dos recursos familiares, que puderam ser alocados aos seus irmãos e irmãs que estavam estudando. Além disso, os jovens, ao não estudarem, podem exercer atividades remuneradas, aumentando o orçamento das famílias e possibilitando um maior gasto com educação dos irmãos e irmãs que freqüentam a escola.

O sinal do parâmetro estimado de Filhtot 2 foi negativo e significativo (Tabela 2). Isso significa que as despesas com educação cresceram com o número de filhos e filhas e depois diminuíram, tendo a forma de uma parábola com vértice para cima. Este resultado condiz com a expectativa de que uma família pode priorizar a alocação de recursos essenciais à sobrevivência da prole em detrimento da educação, quando ela conta com grande número de crianças.

\subsection{As estimativas dos parâmetros das demais variáveis}

Alguns resultados de outras variáveis de controle são discutidos. Dentre eles, os mais importantes são a renda per capita da família e a educação paterna, Logrendper, Escolrefer e Escolconj.

O parâmetro estimado de Logrendper foi positivo e significativo (Tabela 2). Isso pode refletir a menor restrição orçamentária das famílias com rendas maiores, o que significa maior disponibilidade de recursos para a alocação em educação dos filhos e filhas (Barros 2001, Tansel e Bircan 2006, Kingdon 2005).

Os parâmetros estimados para a escolaridade da pessoa de referência e do cônjuge, Escolrefer e Escolconj, foram positivos e significativos (Tabela 2). Isso corrobora a percepção de que maior escolaridade paterna faz a família

\footnotetext{
5 Todas as regressões também foram estimadas por Mínimos Quadrados e os resultados não conflitaram com as conclusões do trabalho. Para maiores detalhes da comparação entre Mínimos Quadrados e o Modelo Tobit ver Wooldridge (2002, pp.527-529).
} 
Tabela 2: Resultados do modelo Tobit (Coeficientes e Efeitos marginais não condicionais) - variável dependente: logaritmo das despesas com educação das famílias $^{a}$ (continua)

\begin{tabular}{|c|c|c|}
\hline Variável & Coeficientes & $\begin{array}{c}\text { Efeitos } \\
\text { marginais não } \\
\text { condicionais }^{b}\end{array}$ \\
\hline Filhomatr7_10 & $\begin{array}{l}0,696^{* *} \\
(0,055)\end{array}$ & $\begin{array}{l}0,654^{* *} \\
(0,052)\end{array}$ \\
\hline Filhamatr7_10 & $\begin{array}{l}0,773^{* *} \\
(0,055)\end{array}$ & $\begin{array}{l}0,727^{* *} \\
(0,051)\end{array}$ \\
\hline Filhomatr11_14 & $\begin{array}{l}0,824^{* *} \\
(0,054)\end{array}$ & $\begin{array}{l}0,774^{* *} \\
(0,051)\end{array}$ \\
\hline Filhamatr11_14 & $\begin{array}{l}0,831^{* *} \\
(0,054)\end{array}$ & $\begin{array}{l}0,781^{* *} \\
(0,050)\end{array}$ \\
\hline Filhomatr15_20 & $\begin{array}{l}0,722^{* *} \\
(0,052)\end{array}$ & $\begin{array}{l}0,679^{* *} \\
(0,042)\end{array}$ \\
\hline Filhamatr15_20 & $\begin{array}{l}0,903^{* *} \\
(0,053)\end{array}$ & $\begin{array}{l}0,848^{* *} \\
(0,050)\end{array}$ \\
\hline Filhonaomatr7_10 & $\begin{array}{l}0,73^{* *} \\
(0,199)\end{array}$ & $\begin{array}{l}0,686^{* *} \\
(0,187)\end{array}$ \\
\hline Filhanaomatr7_10 & $\begin{array}{c}0,54^{*} \\
(0,259)\end{array}$ & $\begin{array}{l}0,507^{*} \\
(0,244)\end{array}$ \\
\hline Filhonaomatr11_14 & $\begin{array}{l}0,399^{*} \\
(0,204)\end{array}$ & $\begin{array}{l}0,381^{*} \\
(0,197)\end{array}$ \\
\hline Filhanaomatr11_14 & $\begin{array}{l}0,409 \\
(0,265)\end{array}$ & $\begin{array}{c}0,39 \\
(0,256)\end{array}$ \\
\hline Filhonaomatr15_20 & $\begin{array}{l}0,423^{* *} \\
(0,066)\end{array}$ & $\begin{array}{l}0,397^{* *} \\
(0,062)\end{array}$ \\
\hline Filhanaomatr15_20 & $\begin{array}{l}0,502^{* *} \\
(0,076)\end{array}$ & $\begin{array}{l}0,472^{* *} \\
(0,071)\end{array}$ \\
\hline Membro0_5 & $\begin{array}{l}0,028 \\
(0,072)\end{array}$ & $\begin{array}{l}0,026 \\
(0,067)\end{array}$ \\
\hline Membro6_10 & $\begin{array}{l}0,161 \\
(0,128)\end{array}$ & $\begin{array}{l}0,151 \\
(0,121)\end{array}$ \\
\hline Membro11_14 & $\begin{array}{l}0,104 \\
(0,157)\end{array}$ & $\begin{array}{l}0,098 \\
(0,148)\end{array}$ \\
\hline Membro15_20 & $\begin{array}{l}0,499^{* *} \\
(0,083)\end{array}$ & $\begin{array}{l}0,469^{* *} \\
(0,078)\end{array}$ \\
\hline Membro21_27 & $\begin{array}{l}0,125^{*} \\
(0,054)\end{array}$ & $\begin{array}{l}0,117^{* *} \\
(0,060)\end{array}$ \\
\hline Membro28_61 & $\begin{array}{l}0,194^{* *} \\
(0,052)\end{array}$ & $\begin{array}{l}0,182^{* *} \\
(0,049)\end{array}$ \\
\hline Membro62 & $\begin{array}{l}0,314 \\
(0,057)\end{array}$ & $\begin{array}{l}0,295 \\
(0,054)\end{array}$ \\
\hline Filhtot2 & $\begin{array}{l}0,069^{* *} \\
(0,008)\end{array}$ & $\begin{array}{l}0,065^{* *} \\
(0,008)\end{array}$ \\
\hline Logrendper & $\begin{array}{l}0,944^{* *} \\
(0,022)\end{array}$ & $\begin{array}{l}0,887^{* *} \\
(0,021)\end{array}$ \\
\hline Exclupriv & $\begin{array}{l}1,295^{* *} \\
(0,047)\end{array}$ & $\begin{array}{l}1,245^{* *} \\
(0,046)\end{array}$ \\
\hline Referenfem & $\begin{array}{l}0,044 \\
(0,058)\end{array}$ & $\begin{array}{l}0,042 \\
(0,054)\end{array}$ \\
\hline Escolrefer & $\begin{array}{l}0,05^{* *} \\
(0,005)\end{array}$ & $\begin{array}{l}0,047^{* *} \\
(0,005)\end{array}$ \\
\hline
\end{tabular}


Tabela 2: Resultados do modelo Tobit (Coeficientes e Efeitos marginais não condicionais) - variável dependente: logaritmo das despesas com educação das famílias. ${ }^{a}$ (conclusão)

\begin{tabular}{|c|c|c|}
\hline Variável & Coeficientes & $\begin{array}{l}\text { Efeitos } \\
\text { marginais não } \\
\text { condicionais }^{b}\end{array}$ \\
\hline Escolconj & $\begin{array}{l}0,047^{* *} \\
(0,005)\end{array}$ & $\begin{array}{l}0,045^{* *} \\
(0,005)\end{array}$ \\
\hline Terconj & $\begin{array}{l}0,276^{* *} \\
(0,083)\end{array}$ & $\begin{array}{l}0,261 \\
(0,079)\end{array}$ \\
\hline Preta & $\begin{array}{l}0,356^{* *} \\
(0,061)\end{array}$ & $\begin{array}{l}0,338^{* *} \\
(0,058)\end{array}$ \\
\hline Amarela & $\begin{array}{l}0,388 \\
(0,216)\end{array}$ & $\begin{array}{l}0,358 \\
(0,196)\end{array}$ \\
\hline Parda & $\begin{array}{l}0,022 \\
(0,036)\end{array}$ & $\begin{array}{l}0,021 \\
(0,034)\end{array}$ \\
\hline Nordeste & $\begin{array}{l}0,201^{* *} \\
(0,042)\end{array}$ & $\begin{array}{l}0,188^{* *} \\
(0,039)\end{array}$ \\
\hline Norte & $\begin{array}{l}0,615^{* *} \\
(0,067)\end{array}$ & $\begin{array}{l}0,563^{* *} \\
(0,059)\end{array}$ \\
\hline Sul & $\begin{array}{l}0,285^{* *} \\
(0,044)\end{array}$ & $\begin{array}{l}0,266^{* *} \\
(0,041)\end{array}$ \\
\hline Centro Oeste & $\begin{array}{l}0,272^{* *} \\
(0,061)\end{array}$ & $\begin{array}{l}0,253^{* *} \\
(0,056)\end{array}$ \\
\hline Urbana & $\begin{array}{l}0,242^{* *} \\
(0,047)\end{array}$ & $\begin{array}{l}0,229^{* *} \\
(0,045)\end{array}$ \\
\hline Constante & $\begin{array}{l}4,535^{* *} \\
(0,163)\end{array}$ & - \\
\hline Sigma & $\begin{array}{c}1,59 \\
(0,012) \\
\end{array}$ & - \\
\hline Log-verossimilhança & -21939.626 & - \\
\hline $\mathrm{R} 2$ & 0.139 & - \\
\hline $\mathrm{F}$ & - & - \\
\hline $\operatorname{LR} \chi^{2}$ & 7056.62 & - \\
\hline Observações & 11386 & - \\
\hline Observações censuradas & 2066 & - \\
\hline
\end{tabular}

Fonte: Microdados da Pesquisa de Orçamentos Familiares de 2002-2003.

* significância a 5\%

** significância a $10 \%$

${ }^{a}$ Os resultados estão ponderados pelo fator de expansão da amostra.

${ }^{b} \mathrm{O}$ efeito marginal da variável explicativa Logrendper é elasticidade-renda estimada. Para as demais variáveis explicativas pode-se aplicar a fórmula [exp(c)-1]100, sendo c o valor do efeito marginal. Com isso, pode-se obter a variação percentual da variável dependente dada a variação em uma unidade da variável explicativa, para as variáveis contínuas. Para as variáveis binárias é a diferença percentual em relação à variável omitida. 
Tabela 3: Resultados dos testes de Wald as diferenças entre os parâmetros de filhos e filhas matriculados segundo as faixas etárias. ${ }^{a}$

\begin{tabular}{lccc}
\hline & Filhomatr7_10 & Filhomatr11_14 & Filhomatr15_20 \\
\hline Filhamatr7_10 & pró-feminina a 5\% & - & - \\
Filhamatr11_14 & - & não significativa & - \\
Filhamatr15_20 & - & - & pró-feminina a 1\% \\
\hline
\end{tabular}

Fonte: Microdados da Pesquisa de Orçamentos Familiares de 2002-2003.

${ }^{1}$ Os resultados estão ponderados pelo fator de expansão da amostra.

gastar mais com educação (Tansel e Bircan 2006). Entre os motivos para esse fato está a percepção que os pais mais educados têm dos benefícios futuros da educação de seus filhos ou filhas. Além de que, os pais podem perceber a educação de seus filhos e filhas como um bem de consumo, um produto que lhes dá prazer por si só (Barros 2001).

A presença de outros membros da família foi significativa somente nas faixas etárias entre 15 e 61 anos (Tabela 2). Neste caso a presença de uma pessoa a mais, provocou um aumento das despesas familiares com educação. O período de 15 a 61 anos de idade coincide com aquele em que as pessoas mais participam do mercado de trabalho, portanto estando mais aptas a contribuir com o orçamento familiar, o que pode ter resultado na significância e nos sinais obtidos.

Os atributos de cor ou raça da pessoa de referência não foram todos significativos (Tabela 2). Em relação às famílias com pessoas de referência branca, os parâmetros estimados de Parda e Amarela não foram significativos, mas o parâmetro estimado para Preta foi positivo e significativo.

Os efeitos das características regionais foram significativos (Tabela 2). Os parâmetros das variáveis regionais tiveram sinais negativos e significativos a $1 \%$. Assim, o fato de uma família não residir no Sudeste implicaria gastar menos com educação.

A área de residência da família teve um efeito significativo sobre as despesas totais com educação (Tabela 2). O parâmetro estimado foi significativo e negativo. Sabe-se que a origem socioeconômica das crianças rurais as coloca em desvantagem em relação às crianças urbanas (Soares 2006). E mais, as escolas rurais estão em pior situação em relação às escolas urbanas quanto a equipamentos e capacitação de professores (Soares 2006). Esses dois fatores podem levar as famílias rurais e urbanas a se comportarem diferentemente quanto às decisões de alocação dos recursos educacionais dos filhos e filhas. Portanto, controladas todas as demais variáveis, as famílias rurais se veriam obrigadas a dispor de mais recursos para que filhos e filhas estudassem. Uma regressão Tobit na qual foram controladas apenas as variáveis sobre filhos e filhas matriculados, não matriculados, demais membros da família e área de residência produziu um parâmetro estimado positivo e significativo para Urbana. Quando controlados, ainda, Logrendper, Escolrefer e Escolconj, o parâmetro estimado de urbano foi negativo e significativo. Isso pode significar que, para um mesmo nível de escolaridade da pessoa de referência, cônjuge e renda per capita, as famílias rurais estariam mais propensas a gastar com educação, controladas também as variáveis demográficas do modelo.

O sexo da pessoa de referência não influenciou as decisões familiares de gastar com educação (Tabela 2). O parâmetro estimado para Referenfem não 
foi significativo, não fornecendo nenhuma evidência da existência de diferença nas decisões de despesas proveniente do sexo da pessoa de referência.

A presença de cônjuge na família impactou significativamente as decisões familiares de gastar com educação, segundo as estimativas do modelo Tobit (Tabela 2). O parâmetro estimado foi significativo e negativo.

\section{Resultados dos modelos Tobit para os gastos com diferentes itens de despesas educacionais}

Nas quatro regressões dos grupos de itens, os parâmetros estimados para filhos e filhas matriculados foram positivos e significativos (Tabela 4). Assim, a presença de um filho ou filha matriculado representou um aumento do valor esperado da variável dependente, para qualquer grupo de despesas considerado.

A presença de filhos e filhas matriculados influenciou significativamente as "Mensalidades escolares" apenas quando estes tinham acima de 10 anos (Tabela 4). Na faixa etária de 11 a 14 anos a presença de um menino apresentou um impacto maior sobre o pagamento de mensalidades, do que a presença de uma menina (Tabela 5). Na faixa etária acima de 14 anos, ocorreu o contrário, a presença de uma menina impactou mais as despesas com mensalidades do que a presença de um menino (Tabela 5). A literatura indica maior defasagem idade-série masculina em todas as faixas etárias, bem como maior evasão masculina das escolas a partir dessa faixa etária. É de se esperar que tal evasão ocorra geralmente nas escolas públicas, freqüentadas por jovens de famílias com menores rendimentos e que, por isso, apresentam maior probabilidade de abandonar os estudos para trabalhar. No entanto, mesmo nas famílias que pagam mensalidades escolares, um filho matriculado com idade superior a 14 anos, pode implicar menor gasto do que uma filha matriculada, com a mesma faixa etária. Isso pode ocorrer porque os rapazes podem freqüentar escolas privadas mais baratas, por exemplo, escolas privadas noturnas, que possibilitam que trabalhem. Ou ainda, caso a defasagem idade-série masculina ocorra nas escolas privadas, implicaria jovens matriculados no ensino fundamental ao invés do ensino médio e, provavelmente, em menor custo de mensalidades.

Os resultados obtidos das comparações dos parâmetros estimados dos filhos e filhas, quando se procurou explicar os desembolsos com "Artigos escolares, livros e materiais bibliográficos" ou "Outras despesas escolares", indicaram que as famílias não discriminaram os gastos com os bens necessários à freqüência as aulas em função do gênero (Tabela 5). Ou seja, uma vez matriculado, um filho ou uma filha, houve gastos com uniforme, bibliografia, taxas etc., independente do gênero da criança ou jovem matriculado. O mesmo não ocorreu quando se tratava de gastar com cursos de idiomas, profissionalizantes, de informática, atividades físicas, desportivas e culturais e as variadas formas de formação complementar dos jovens, pois nestes casos os gastos com filhas foram significativamente maiores (Tabela 5).

\subsection{As estimativas dos parâmetros das demais variáveis de controle para os gastos com diferentes itens de despesas educacionais}

Os sinais dos parâmetros estimados de Logrendper foram positivos e significativos, em todas as regressões estimadas (Tabela 4). Confirma-se que uma 
menor restrição orçamentária implicou aumento dos gastos com educação, independente do grupo de itens.

As escolaridades da pessoa de referência e do cônjuge tiveram comportamentos semelhantes (Tabela 4). Os parâmetros estimados para Escolrefer e Escolconj não foram significativos para Outras_desp como variável dependente, mas foram positivos e significativos em todas as outras regressões. Os resultados indicaram uma tendência de gastos maiores com a educação dos filhos e filhas, quando a pessoa de referência e o cônjuge eram mais escolarizados.

Os sinais dos parâmetros estimados para as variáveis que representaram a presença de outros membros da família não foram significativos em todas as estimativas (Tabela 4). Quando os sinais foram significativos, houve sinais positivos e negativos. A significância ocorreu, na maioria das vezes, para as faixas etárias em que as pessoas eram maiores de 15 anos. Nestes casos, os parâmetros estimados também foram positivos. Para outros membros da família abaixo de 15 anos, houve três casos de significância e sinais negativos: para parâmetros estimados de Membro0_5, para variável dependente de Mensal_escol; e para Membro6_10 quando a variável dependente foi Outras_desp e, também, quando foi Curs_naoregular.

O sexo da pessoa de referência influenciou as decisões familiares de gastar com educação apenas quando o desembolso era para cursos não regulares (Tabela 4). A maior parte dos parâmetros estimados não foi significativa, não fornecendo evidências da influência nas decisões de despesas provenientes do sexo da pessoa de referência.

A presença do cônjuge foi significativa em duas regressões. Para Mensal_escol e Outras_desp como variáveis dependentes, os parâmetros estimados de Terconj foram negativos e significativos (Tabela 4). Com Art_livros e Outras_desp como variáveis dependentes, ter cônjuge não foi significativa.

As características regionais afetaram as despesas das famílias com educação também quando elas foram divididas em grupos (Tabela 4). Os parâmetros estimados das binárias das regiões foram negativos e significativos. $\mathrm{O}$ único parâmetro estimado não significativo foi para Nordeste, com Art_livros como variável dependente. Desta forma, as famílias não residentes na Região Sudeste tenderam a gastar menos com educação.

As características de cor ou raça da pessoa de referência não exerceram uma influência sistemática sobre as despesas educacionais, quando elas foram subdivididas (Tabela 4). O parâmetro estimado de Preta não foi significativo com Mensal_escol como variável dependente. Nas outras regressões teve significância e sinal positivo. O parâmetro estimado de Amarela só teve significância para Mensal_escol como variável dependente, tendo sinal negativo. E o parâmetro estimado de Parda foi significativo apenas quando Art_livros era a variável dependente.

\section{Conclusões}

Como se observou, existe um ambiente favorável à escolarização feminina no Brasil, diferente do que ocorre na maioria dos países PersonNameProductIDem desenvolvimento. Mesmoem desenvolvimento. Mesmo diante de tal quadro, este trabalho procurou identificar um possível viés de gênero nas escolhas paternas de gastar recursos familiares na formação educacional de 


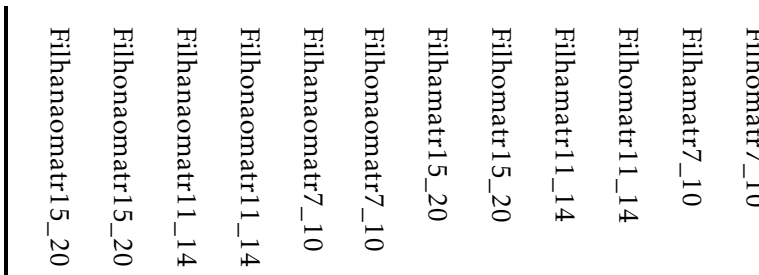

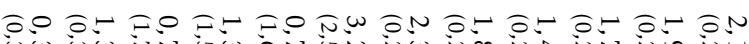

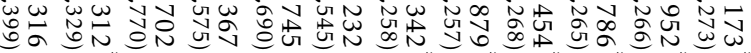

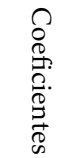

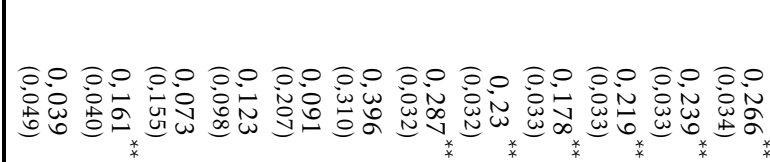

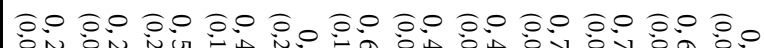

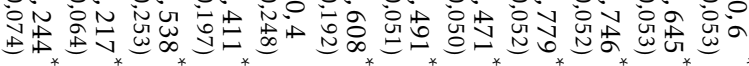

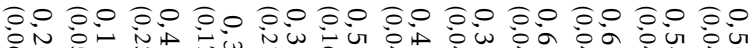

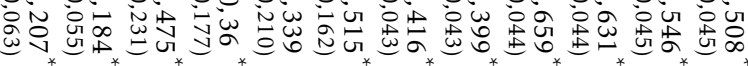

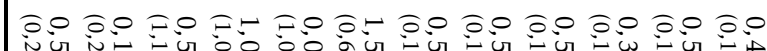

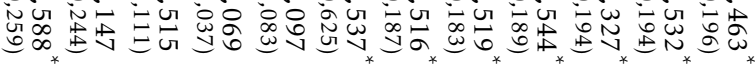

दि:

i $\stackrel{2}{2} \stackrel{0}{\circ}$

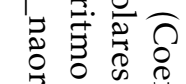

.

o̊ 各全

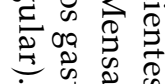

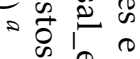

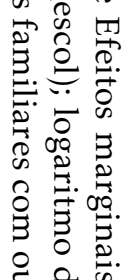

㱏命

ती के ?

क क

芯节

क : 5.

ठै

$\stackrel{0}{0}$

$\begin{array}{lll}0 & \infty & 1 \\ 0 & 0 & 1 \\ \infty & 0 & 0\end{array}$

○ิ

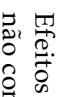

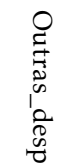

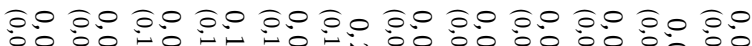

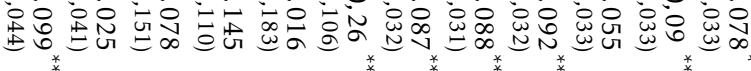

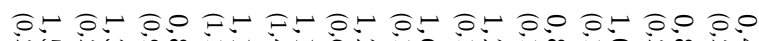

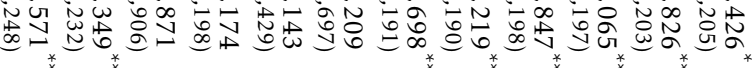

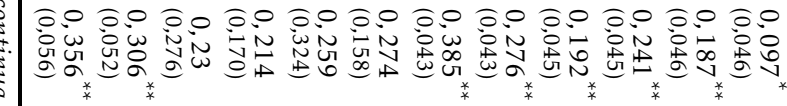




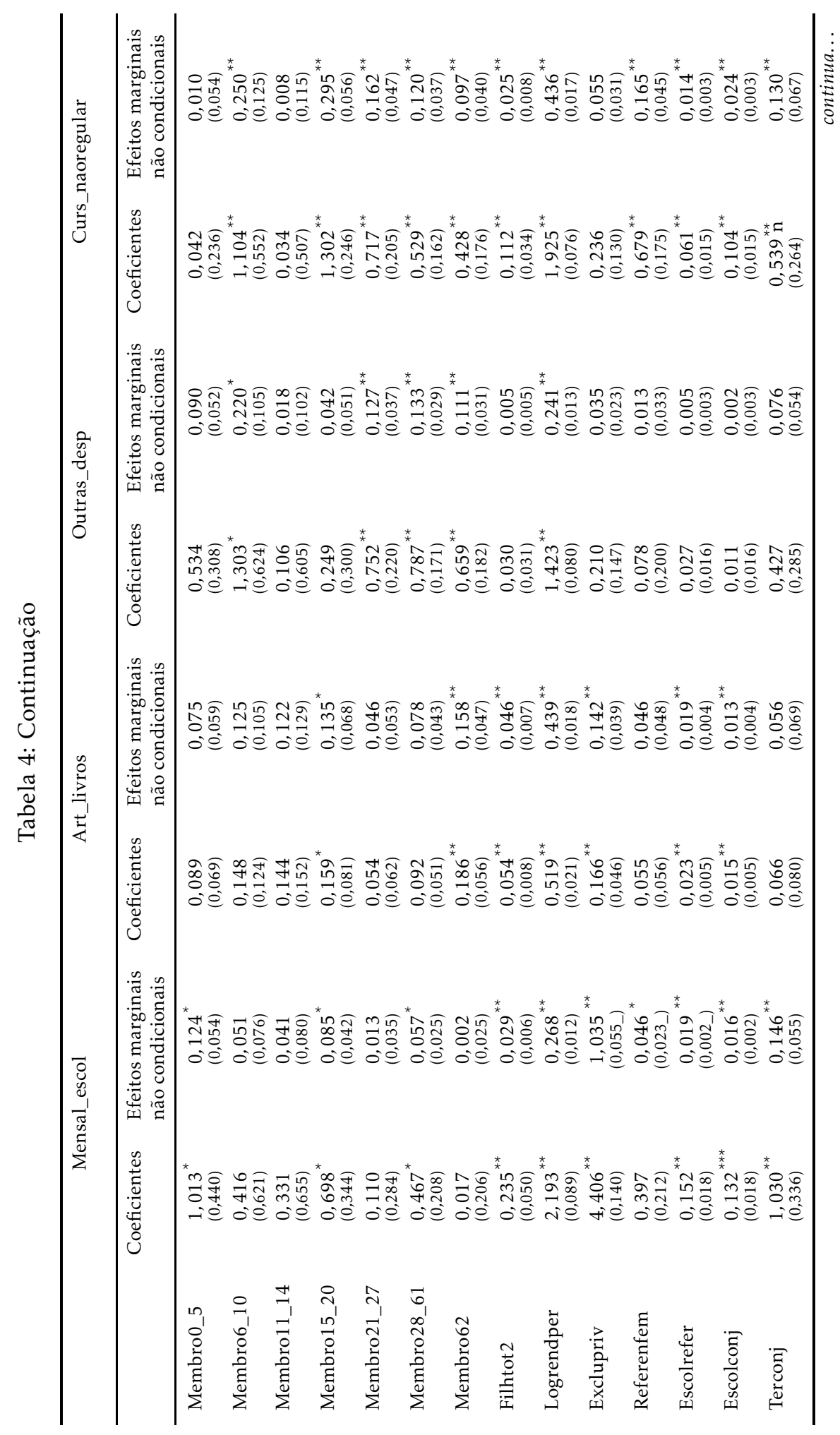




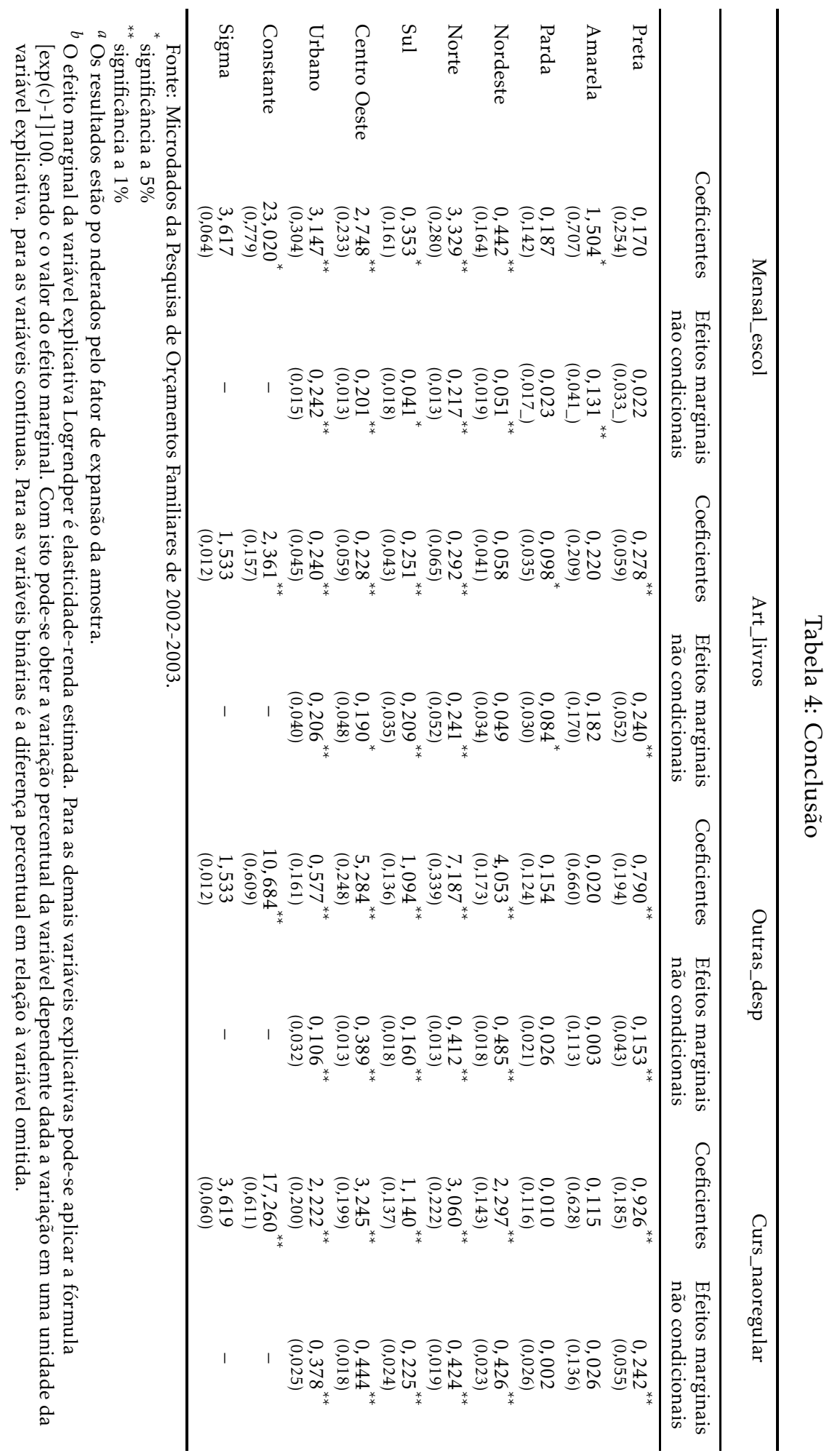


Tabela 5: Resultados dos testes de Wald para as diferenças entre os parâmetros estimados de filhos e filhas matriculados em cada faixa etária - modelos Tobit. $^{a}$

\begin{tabular}{lccc}
\hline \multicolumn{4}{c}{ Variável dependente: Mensal_escol } \\
\hline \multirow{4}{*}{ Filhamatr7_10 } & Filhomatr7_10 & Filhomatr11_14 & Filhomatr15_20 \\
\cline { 2 - 4 } Filhamatr11_14 & não significativa & - & - \\
Filhamatr15_20 & - & pró-masculina a 5\% & pró-feminina a 1\% \\
\hline \multicolumn{5}{c}{ Variável dependente: Art_livros } \\
\hline \multirow{5}{*}{ Filhomatr7_10 } & Filhomatr11_14 & Filhomatr15_20 \\
\cline { 2 - 4 } Filhamatr7_10 & não significativa & - & - \\
Filhamatr11_14 & - & não significativa & - \\
Filhamatr15_20 & - & - & não significativa \\
\hline \multicolumn{5}{c}{ Variável dependente: Outras_desp } \\
\hline Filhomatr7_10 & Filhomatr11_14 & Filhomatr15_20 \\
\cline { 2 - 4 } Filhamatr7_10 & não significativa & - & - \\
Filhamatr11_14 & - & não significativa & - \\
Filhamatr15_20 & - & - & não significativa \\
\hline \multicolumn{5}{c}{ Variável dependente: Curs_naoregular } \\
\hline \multicolumn{5}{c}{ Filhomatr7_10 } & Filhomatr11_14 & Filhomatr15_20 \\
\cline { 2 - 4 } Filhamatr7_10 & pró-feminina a 1\% & - & - \\
Filhamatr11_14 & - & não significativa & pró-feminina a 1\% \\
Filhamatr15_20 & - & - & \\
\hline Fonte:Microdados da Pesquisa de Orçamentos Familiares de 2002-2003 \\
a Os resultados estão ponderados pelo fator de expansão da amostra
\end{tabular}

filhos e filhas, que pudesse ser desfavorável às jovens.

Os resultados econométricos indicaram que filhos e filhas matriculados impactaram positivamente os gastos familiares com educação. Esta relação ocorreu quando foram analisadas as despesas totais com educação ou, ainda, quando se tratou dos gastos com grupos específicos de itens educacionais. Os filhos e filhas não matriculados não rivalizaram com os matriculados quanto às despesas com educação, pois impactaram positivamente as despesas totais com educação ou não foram significativos quando foram analisados os gastos com itens educacionais específicos. O aumento do número total de filhos e filhas, porém, pressionou as despesas a taxas decrescentes, resultado obtido também na análise dos gastos com os grupos de itens educacionais específicos.

Os resultados econométricos reforçam o cenário favorável à escolarização feminina. A análise das despesas totais com educação indicou diferenças significativas no impacto causado por filhos e filhas matriculados em duas faixas etárias, com viés pró-feminino. A análise dos gastos com grupos de itens educacionais indicou diferenças significativas nos gastos com mensalidades escolares para duas faixas etárias, de 11 a 14 anos e de 15 a 20 anos, com viés pró-feminino na última faixa. Quando foram analisados os gastos com cursos não regulares, observaram-se diferenças significativas de 6 a 10 anos e de 11 a 14 anos, ambas pró-femininas. Entre os demais itens não houve diferenças significativas. Os resultados indicam que a formação das jovens não 
sofreu discriminação no que tange à disposição das famílias de gastarem com a formação de sua prole. Ou seja, não existe indicação de que os pais gastem menos na formação das filhas, o que seria uma forma não perceptível de discriminação quando se observa os indicadores de progressão escolar e taxas de matrícula.

A diversidade regional pode ser explorada de outra forma. No presente estudo, variáveis binárias foram utilizadas para controlar as diferenças regionais, mas esse controle pode não ser suficiente. Seria interessante questionar se os gastos familiares com educação também são condizentes com o ambiente favorável à escolarização feminina, quando as diferentes regiões do Brasil são observadas separadamente.

A diversidade regional pode ser explorada de outra forma. No presente estudo, variáveis binárias foram utilizadas para controlar as diferenças regionais, mas esse controle pode não ser suficiente. Seria interessante questionar se os gastos familiares com educação também são condizentes com o ambiente favorável à escolarização feminina, quando as diferentes regiões do Brasil são observadas separadamente.

\section{Referências Bibliográficas}

D. Alves. Gastos com saúde: uma análise por domicílios para a cidade de são paulo. Pesquisa e Planejamento Econômico, 31:479-494, December 2001.

R. P. Barros. Determinantes do desempenho educacional no brasil. Technical report, IPEA, 2001.

R. P. Barros e R. S. P. Mendonça. Infância e adolescência no brasil: as consequências da pobreza diferenciais por gênero, faixa etária e região de residência. Technical report, IPEA, 1990.

K. I. Beltrão. Acesso à educação: diferenciais entre sexos. Technical report, IPEA, 2002.

K. I. Beltrão. Dinâmica populacional brasileira na virada do século xx. Technical report, IPEA, 2004.

K. I. Beltrão e M. D. P. Teixeira. O vermelho e o negro: viés de cor e gênero nas carreiras universitárias. Technical report, IPEA, 2005.

B. F. Bertasso. O consumo alimentar dos brasileiros metropolitanos. Technical report, IPEA, 2007.

F. K. Butcher e A. Case. The effect of sibling sex composition on women's education and earnings. Quartely Journal of Economics, 3:531-563, 1994.

C. H. Conseuil. Decisões críticas em idades críticas: a escolha dos jovens entre estudo e trabalho no brasil e em eoutros países da américa latina. Technical report, IPEA, 2001.

A. Garg e J. Morduch. Sibling rivalry. Technical report, Harvard Institute for International Development, 1998.

R. G. M. R. Gomes. Tipologia das famílias residentes no estado do rio de janeiro segundo a estrutura das despesas de consumo. Master's thesis, Escola Nacional de Ciências Estatísticas, 2005. 
H. S. Houthakker. New evidence on demand elasticities. Econometrica, 33 (2):277-288, 1965.

IBGE. Pesquisa de orçamentos familiares 2002-2003: primeiros resultados: Brasil e grandes regiões. Technical report, InstitutoBrasileirodeGeografiaeEstatistica, 2004.

G. G. Kingdon. Where has all the bias gone? detecting gender bias in the intrahousehold allocation of educational expenditure. Economic Development and Cultural Change, 53:409-451, 2005.

G. P. Mahan. The demand for residential telephone service. PhD thesis, Michigan State University, 1979.

L. J. Marteleto. O papel do tamanho da família na escolaridde dos jovens. Revista Brasileira de Estudos de População, 19:160-177, 2002.

J. A. S. Medeiros. Curvas de engel e transformação de box-cox: uma aplicação aos dispêndios em alimentação e educação na cidade de são paulo. Technical Report 3, Pesquisa e Planejamento Econômico, 1978.

J. Morduch. Sibling rivalry in africa. American Economic Review, 90(3):405409, 2000.

H. Ono. Are sons and daughters substitutable? allocation of family resources in contemporary japan. Journal of the Japanese and International Economies, 18 (2):143-160, 2004.

P. Pierotti. Sons and daughters: evidence from educational achievement outcomes in Brazil. PhD thesis, University of Chicago, 2004.

D. Post. Region, poverty, sibship, and genger inequality in mexican education: will targeted welfare policy make a difference for girls? Gender and Society, 15(3):468-489, 2001.

S. Prais. Measuring social mobility. Journal of Royal Statistical Society, A: 56-66, 1955.

S. Soares. A educação no brasil rural. Technical report, INEP, 2006.

A. Tansel e F. Bircan. Demand for education in turkey: a tobit analysis of private toutoring expenditures. Economics of Education Review, 25:303-313, 2006.

Naciones Unidas. Objetivos de desarrollo del milleno: informe 2005. Technical report, Departamento de Información Pública de las Naciones Unidas, 2005.

J. M. Wooldridge. Econometric Analysis of Cross Section and Panel Data. The MIT Press, 2002. 


\section{Apêndice A}

Discriminação dos itens referentes às despesas com educação - Questionário 4 da Pesquisa de Orçamentos Familiares 2002-20031. ${ }^{a}$

\begin{tabular}{|c|c|c|}
\hline \multirow[b]{2}{*}{$\begin{array}{l}\text { Mensalidades } \\
\text { escolares }\end{array}$} & $\begin{array}{l}\text { Cursos } \\
\text { regulares }\end{array}$ & $\begin{array}{l}\text { curso regular de primeiro grau, curso regular de } 1^{\circ} \text { grau, } \\
\text { curso regular de segundo grau, curso regular de } 2^{\circ} \text { grau, } \\
\text { curso regular de terceiro grau, curso regular de } 3^{\circ} \text { grau }\end{array}$ \\
\hline & $\begin{array}{l}\text { Mestrados e } \\
\text { doutorados }\end{array}$ & $\begin{array}{l}\text { pós-graduação (mestrado), curso de pós-graduação } \\
\text { (mestrado), especialização (mestrado), curso de } \\
\text { especialização (mestrado), mestrado (curso), curso de } \\
\text { mestrado, pós-graduação (doutorado), curso de } \\
\text { pós-graduação (doutorado), especialização (doutorado), } \\
\text { curso de especialização (doutorado), doutorado (curso), } \\
\text { curso de doutorado }\end{array}$ \\
\hline \multirow{3}{*}{$\begin{array}{l}\text { Artigos } \\
\text { escolares, } \\
\text { livros e } \\
\text { materiais } \\
\text { bibliográficos }\end{array}$} & $\begin{array}{l}\text { Uniforme } \\
\text { escolar e } \\
\text { Materiais } \\
\text { didáticos } \\
\text { diversos }\end{array}$ & $\begin{array}{l}\text { materiais didáticos e escolares, uniforme escolar, pasta } \\
\text { escolar, merendeira escolar, lancheira escolar, agenda } \\
\text { escolar, mochila escolar, instrumentos e aparelhos de } \\
\text { cursos educativos, aparelhos de cursos educativos, } \\
\text { estetoscópio, tensiometro, aerógrafo, bússola, } \\
\text { instrumentos cirúrgicos de curso, instrumentos de aula } \\
\text { pratica, mapa escolar, tradutor }\end{array}$ \\
\hline & $\begin{array}{l}\text { Livros } \\
\text { escolares } 1^{\circ} \mathrm{e} \\
2^{\circ} \text { Graus }\end{array}$ & $\begin{array}{l}\text { livro escolar de primeiro e segundo graus, livro escolar de } \\
1^{\circ} \text { e } 2^{\circ} \text { grau, livro pre escolar, aluguel de livro de primeiro } \\
\text { grau }\end{array}$ \\
\hline & $\begin{array}{l}\text { Outros } \\
\text { materiais } \\
\text { bibliográficos }\end{array}$ & $\begin{array}{l}\text { assinatura de periódico técnico, livro e revista técnica e } \\
\text { outros livros didáticos, livro técnico, revista técnica, outros } \\
\text { livros didáticos, dicionário, apostila, manual didático, guia } \\
\text { (manual) de vestibular, apostila de supletivo, livro } \\
\text { para-didático, enciclopédia, livro e revista técnica }\end{array}$ \\
\hline \multirow{7}{*}{$\begin{array}{l}\text { Outras } \\
\text { despesas } \\
\text { escolares }\end{array}$} & $\begin{array}{l}\text { Taxas } \\
\text { escolares } \\
\text { diversas }\end{array}$ & $\begin{array}{l}\text { taxas escolares, taxa de material escolar, taxa de exame } \\
\text { biomédico, taxa de transferência escolar, taxas escolares } \\
\text { (diploma, etc.), matricula escolar }\end{array}$ \\
\hline & $\begin{array}{l}\text { Documentos } \\
\text { escolares }\end{array}$ & $\begin{array}{l}\text { certificado de conclusão escolar, documentação escolar } \\
\text { (emolumento), emolumento (despesa de documentação } \\
\text { escolar), ficha modelo } 18 \text { e 19, diploma, carteira de } \\
\text { estudante, caderneta escolar, declaração escolar, cartão } \\
\text { magnético escolar, cartão escolar magnético }\end{array}$ \\
\hline & $\begin{array}{l}\text { Alimentação, } \\
\text { moradia e } \\
\text { transporte } \\
\text { estudantil }\end{array}$ & $\begin{array}{l}\text { transporte escolar, locação de alojamento estudantil, } \\
\text { locação de quarto, locação de vaga (moradia), alimentação } \\
\text { escolar, alimentação na escola }\end{array}$ \\
\hline & $\begin{array}{l}\text { Despesas } \\
\text { escolares } \\
\text { diversas }\end{array}$ & $\begin{array}{l}\text { carne de formatura, formatura (carnet), colação de grau, } \\
\text { festa escolar, convite de formatura, outros artigos de } \\
\text { formatura (beca chapéu etc), excursão escolar, associação } \\
\text { de pais e mestres (apm), circulo de pais e mestres (cpm), } \\
\text { colônia de férias (educação), biblioteca (mensalidade, } \\
\text { multa, etc.), mensalidade de biblioteca, multa de } \\
\text { biblioteca, grêmio estudantil, cota extra escolar, }\end{array}$ \\
\hline & $\begin{array}{l}\text { Berçários e } \\
\text { creches }\end{array}$ & creche, berçário, creche (domicilio particular) \\
\hline & $\begin{array}{l}\text { Congressos, } \\
\text { seminários e } \\
\text { palestras }\end{array}$ & $\begin{array}{l}\text { taxa de congresso, seminário, etc. (educação), congresso } \\
\text { (taxa de inscrição) (educação), seminário (taxa de } \\
\text { inscrição) (educação), palestra educativa (taxa de } \\
\text { inscrição), taxa de inscrição de congresso (educação), taxa } \\
\text { de inscrição de seminário (educação), taxa de inscrição de } \\
\text { palestra educativa }\end{array}$ \\
\hline & $\begin{array}{l}\text { Taxas } \\
\text { diversas }\end{array}$ & $\begin{array}{l}\text { taxa de inscrição de vestibular, inscrição de vestibular } \\
\text { (taxa), taxa de inscrição para concurso (escola técnica,etc.) }\end{array}$ \\
\hline
\end{tabular}


Discriminação dos itens referentes às despesas com educação - Questionário 4 da Pesquisa de Orçamentos Familiares 2002-20031. ${ }^{a}$ (continuação)

\begin{tabular}{|c|c|c|}
\hline \multirow{5}{*}{$\begin{array}{l}\text { Cursos não } \\
\text { regulares }\end{array}$} & $\begin{array}{l}\text { Cursos de } \\
\text { idiomas }\end{array}$ & $\begin{array}{l}\text { curso de idioma (exceto linguafone), curso de espanhol, } \\
\text { curso de inglês, curso de alemão, curso de italiano, curso } \\
\text { de japonês, curso de francês, curso de idioma }\end{array}$ \\
\hline & $\begin{array}{l}\text { Cursos } \\
\text { técnico- } \\
\text { profissiona- } \\
\text { lizantes }\end{array}$ & $\begin{array}{l}\text { curso de cabeleireiro, curso de capacitação, curso de corte } \\
\text { e costura, curso de culinária, curso de desenho, curso de } \\
\text { eletricista, curso de enfermagem, curso de pintura, curso } \\
\text { de secretariado, curso de vigilante, curso preparatório, } \\
\text { curso profissionalizante, curso técnico, curso de mecânica } \\
\text { em refrigeração, datilografia, pré-técnico }\end{array}$ \\
\hline & $\begin{array}{l}\text { Atividades } \\
\text { físicas, } \\
\text { desportivas, } \\
\text { artísticas e } \\
\text { culturais }\end{array}$ & $\begin{array}{l}\text { escolinha ou curso (futebol,voleibol,lutas,basquetebol,etc.), } \\
\text { curso ou escolinha (futebol,voleibol, lutas, } \\
\text { basquetebol,etc.), futebol (escolinha ou curso), voleibol } \\
\text { (escolinha ou curso), tênis (escolinha ou curso), lutas } \\
\text { (escolinha ou curso), basquetebol (escolinha ou curso), } \\
\text { handebol (escolinha ou curso), ginástica, hidroginástica, } \\
\text { academia (musculação), academia (musculação), bale, ioga, } \\
\text { música, curso de dança, curso de teatro, natação, capoeira }\end{array}$ \\
\hline & $\begin{array}{l}\text { Cursos } \\
\text { diversos }\end{array}$ & $\begin{array}{l}\text { curso pré-escolar, curso supletivo, aula particular, curso } \\
\text { em disco ou fita (linguafone), curso em fita cassete, curso } \\
\text { em disco, outros cursos, auto-escola (curso), curso de } \\
\text { direção de veículo, curso de primeiros socorros, primeiros } \\
\text { socorros (curso), curso para excepcional, pré-vestibular, } \\
\text { educação a distancia (cursos), curso de especialização } \\
\text { (extensão) }\end{array}$ \\
\hline & Informática & $\begin{array}{l}\text { software de curso, soft de curso, programa computacional } \\
\text { de curso (software), informática }\end{array}$ \\
\hline
\end{tabular}

Fonte: Pesquisa de Orçamentos Familiares 2002-2003

${ }^{a}$ As agregações dos itens das despesas escolares foram realizadas a critério dos autores 